\title{
Recent Trends in Neurosurgery Career Outcomes in Canada
}

\author{
Michael K. Tso, J. Max Findlay, Stephen P. Lownie, M. Chris Wallace, \\ Brian D. Toyota, Ian G. Fleetwood
}

\begin{abstract}
Background: As with other specialties, Royal College of Physicians and Surgeons of Canada (RCPSC) trainees in Neurosurgery have anecdotally had challenges securing full-time employment. This study presents the employment status, research pursuits, and fellowship choices of neurosurgery trainees in Canadian programs. Methods: RCPSC neurosurgery trainees $(n=143)$ who began their residency training between 1998 and 2008 were included in this study. Associations between year of residency completion, research pursuits, and fellowship choice with career outcomes were determined by Fisher's exact test ( $p<0.05$, statistical significance). Results: In 2015, 60\% and 26\% of neurosurgery trainees had permanent positions in Canada and the USA, respectively. Underemployment, defined as locum and clinical associate positions, pursuit of multiple unrelated fellowships, unemployment, and career change to non-surgical career, was $12 \%$ in 2015 . The proportion of neurosurgery trainees who had been underemployed at some point within 5 years since residency completion was $20 \%$. Pursuit of in-folded research (MSc, PhD, or non-degree research greater than 1 year) was significantly associated with obtaining full employment $(94 \%$ vs. $73 \%, p=0.011)$. However, fellowship training was not significantly associated with obtaining full employment $(78 \%$ vs. $75 \%, p=1.000)$. Conclusions: Underemployment in neurosurgery has become a significant issue in Canada for various reasons. Pursuit of in-folded research, but not fellowship training, was associated with obtaining full employment.
\end{abstract}

RÉSUMÉ: Tendances récentes au Canada en ce qui regarde les possibilités d'emploi en neurochirurgie. Contexte : À l'instar d'autres stagiaires de la médecine spécialisée, des stagiaires en neurochirurgie membres du Collège royal des médecins et des chirurgiens du Canada (CRMCC) ont dit éprouver, selon des données empiriques, des difficultés à obtenir un emploi à plein temps. Cette étude entend présenter la situation professionnelle des stagiaires inscrits dans des programmes canadiens en neurochirurgie ainsi que leurs activités de recherche et leurs choix en matière de bourses de recherche postdoctorale. Méthodes : Des stagiaires membres du CRMCC ayant entrepris leur résidence entre 1998 et 2008 ( $n=143)$ ont été inclus dans cette étude. Les liens pouvant exister entre l'année de résidence complétée, les activités de recherche, les choix en matière de bourses de recherche postdoctorale et les possibilités d'emploi ont été déterminés au moyen du test exact de Fisher (p < 0,05; signification statistique). Résultats : En 2015, $60 \%$ des stagiaires en neurochirurgie du Canada disaient compter sur un poste permanent alors qu'ils étaient $26 \%$ à affirmer la même chose aux États-Unis. Le sous-emploi, défini comme par des postes de suppléant (locum) et de clinicien adjoint, par l'obtention de plusieurs bourses de recherche postdoctorale sans liens apparents, par le chômage et par un changement d'orientation excluant la chirurgie, atteignait $12 \%$ la même année. La proportion de stagiaires disant avoir été sous-employés à un moment ou un autre au cours des 5 années de leur résidence était par ailleurs de $20 \%$. Le fait de mener un projet de recherche dans le cadre de sa résidence (M.Sc., Ph.D. ou en dehors des cycles supérieurs pendant au moins 12 mois) était clairement associé à l'obtention d'un emploi à temps plein $(94 \%$ contre $73 \% ; \mathrm{p}=0,011)$. Cela dit, une formation offerte à la suite de l'obtention d'une bourse de recherche postdoctorale n'a pas été associée de manière notable à l'obtention d'un emploi à temps plein (78\% contre $75 \% ; \mathrm{p}=1,000)$. Conclusions : Le sous-emploi en neurochirurgie est désormais un enjeu important au Canada, et ce, pour toutes sortes de raisons. Contrairement aux formations liées à l'obtention d'une bourse de recherche postdoctorale, le fait de mener un projet de recherche régulier a été associé à l'obtention d'un emploi à temps plein.

Keywords: Neurosurgery, Employment, Canada, Research, Fellowship

doi:10.1017/cjn.2019.22

Can J Neurol Sci. 2019; 46: 436-442

\section{INTRODUCTION}

For more than a decade, career opportunities in neurosurgery have been an ongoing topic of discussion among Canadian neurosurgery residents, fellows, staff, and even medical students. ${ }^{1}$ Since 1998, the American Board of Neurological Surgery (ABNS) has restricted board eligibility for trainees in Royal College of Physicians and Surgeons of Canada (RCPSC) programs. Neurosurgery residents who entered a Canadian neurosurgery residency program after July 16, 1997 are not ABNS-eligible (board eligible) nor have the ability to become ABNS-certified (board

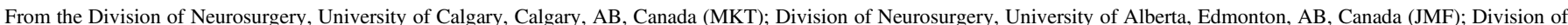

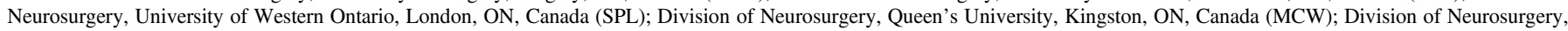
University of British Columbia, Vancouver, BC, Canada (BDT); Division of Neurosurgery, University of British Columbia, Victoria, BC, Canada (IGF)

Received September 29, 2018. Final Revisions Submitted February 8, 2019. Date of Acceptance February 19, 2019.

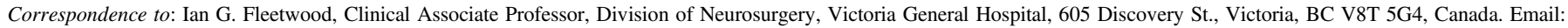
ian.fleetwood@yahoo.ca 
certified). ${ }^{2}$ Residents who began their neurosurgery residency on July 1, 1998 (projected post-graduate year 6 (PGY-6) of 2004) were the first cohort of Canadian neurosurgery residents to be affected by this change.

Career opportunities in neurosurgery have been discussed extensively within the Canadian Neurosurgical Society (CNSS) and during its annual general meetings at the Canadian Neurological Sciences Federation (CNSF) congress. At the June 2012 CNSF Congress in Ottawa, Dr. Chris Wallace chaired a wellattended course focused on the "Neurosurgical Education and Workforce in Canada." In response to ongoing unemployment and underemployment affecting not only neurosurgery, but also many different specialty programs, the RCPSC organized the National Physician Employment Summit in February 2014 with healthcare stakeholders representing many interest groups, including the CNSS. ${ }^{3}$ The purpose of this summit was to determine the scope and magnitude of underemployment in various specialties, to determine the main factors for underemployment, and to conceptualize potential solutions. ${ }^{3}$

There have been several editorials and articles published outlining the impending neurosurgery employment concern. ${ }^{4-8}$ Woodrow et al. analyzed Canadian neurosurgery trainees from 1990 to 2002 and stated that there would be twice as many neurosurgery residents completing residency compared to the predicted number of neurosurgery positions in Canada, while acknowledging the limitations of forecasting healthcare needs. ${ }^{8}$ No article since has provided concrete numbers regarding the career status of Canadian neurosurgery trainees affected by changes in ABNS board eligibility. In this study, we report the employment status of Canadian neurosurgery trainees in the post-ABNS eligibility era. We also analyze the pursuit of research and fellowship training among neurosurgery trainees and determine how these two factors affect employment outcomes.

\section{Methods}

This study included neurosurgery trainees who began training in a Canadian neurosurgery residency program during an 11-year period between 1998 and 2008 inclusive, with completion of PGY-6 projected between 2004 and 2014. All of the neurosurgery trainees in this time period were not eligible to write the ABNS primary examination and were not able to obtain ABNS certification. Only Canadian medical graduates (CMGs) were included in this analysis. Neurosurgery trainees who began their residency prior to 1998 but completed residency in 2004 and onward were not included as they are ABNS board eligible. Neurosurgery trainees who departed their training program prior to completion were also excluded. The length of training in a Canadian neurosurgery residency program is at least 6 years, depending upon pursuit of research interests.

Those who completed training in Canadian neurosurgery residency programs were identified by surveying public domain websites and by personal knowledge, with assistance in identifying all index trainees from current CNSS active and junior members. These websites included provincial College of Physicians and Surgeons websites, hospital and university websites, authorship information from scientific articles listed on Pubmed, mdselect.ca that lists the majority of practicing physicians in Canada, LinkedIn.com, CNSS membership listing, and other

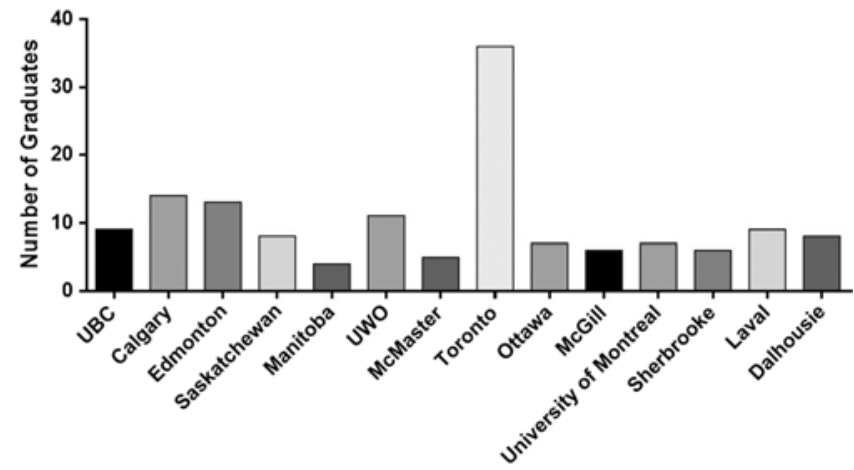

Figure 1: Number of neurosurgery trainees $(n=143)$ with available data for this study based on their home residency training program.

professional association websites. Because the data collection involved gathering public domain information, specific institutional ethical approval was not sought. However, the ethical principles of the Tri-Council Policy Statement 2 were strictly adhered to. ${ }^{9}$

Neurosurgery trainees were stratified based on projected PGY-6 year and neurosurgery training program. Projected PGY-6 year indicates the year in which a resident would have completed neurosurgery residency after the usual 6-year period. Projected PGY-6 year is distinguished from actual PGY-6 year, in which residency completion may be delayed due to reasons such as pursuit of research or a post-graduate degree. The identities of the neurosurgery trainees were anonymized with a numerical coding system. Data points collected included training program location, projected PGY-6 year, actual PGY-6 year, pursuit of research prior to residency training, during residency or postresidency, location of in-folded research, pursuit and location of fellowship, fellowship subspecialty, current employment status as of January 2015, and prior underemployment within 5 years since residency completion. "Underemployment" category was sub-classified into locum/clinical associate positions, pursuit of multiple unrelated fellowships, unemployment, and switch to nonsurgical careers. An academic appointment was defined as one associated with a residency program and university. "Community practice" was used to describe a Canadian neurosurgery position not associated with a residency program. "Private practice" was used to describe a US neurosurgery position not associated with a residency program. "Extended research" was defined as pursuit of non-degree research for more than 1 year. For the purposes of this study, trainees who engaged in research for 1 year or less in a nongraduate degree program were classified as having "no research." "Full employment" status is indicative of no prior underemployment within 5 years of completing residency.

Fisher's exact test was used to determine associations between projected PGY-6 year, research pursuits, and fellowship training with career outcomes. Stata 12.0 (StataCorp LP, College Station, TX) and Prism 6 (Graphpad Software, San Diego, CA) were used for statistical analysis and graph generation, respectively. Statistical significance was defined as $p<0.05$ and statistical trend was defined as $0.05<p<0.10$.

\section{Results}

Overall, 143 eligible neurosurgery trainees who began neurosurgery residency training in Canadian programs from 1998 to 


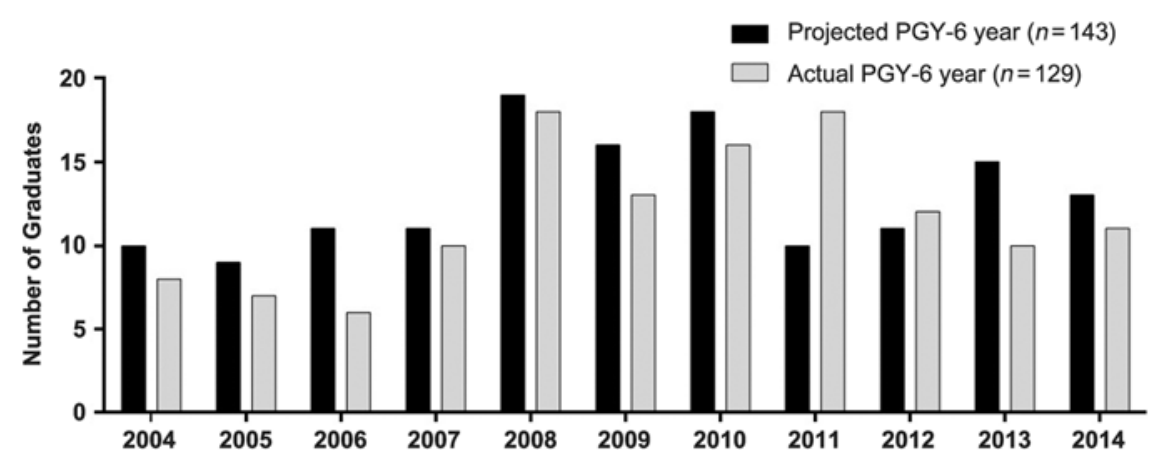

Figure 2: Number of neurosurgery trainees based on projected PGY-6 year $(n=143)$ and actual PGY-6 year $(n=129)$. The number of trainees based on the projected PGY-6 year represents the hypothetical number of trainees graduating that year including the few trainees who pursued in-folded research, which would have lengthened the training time.

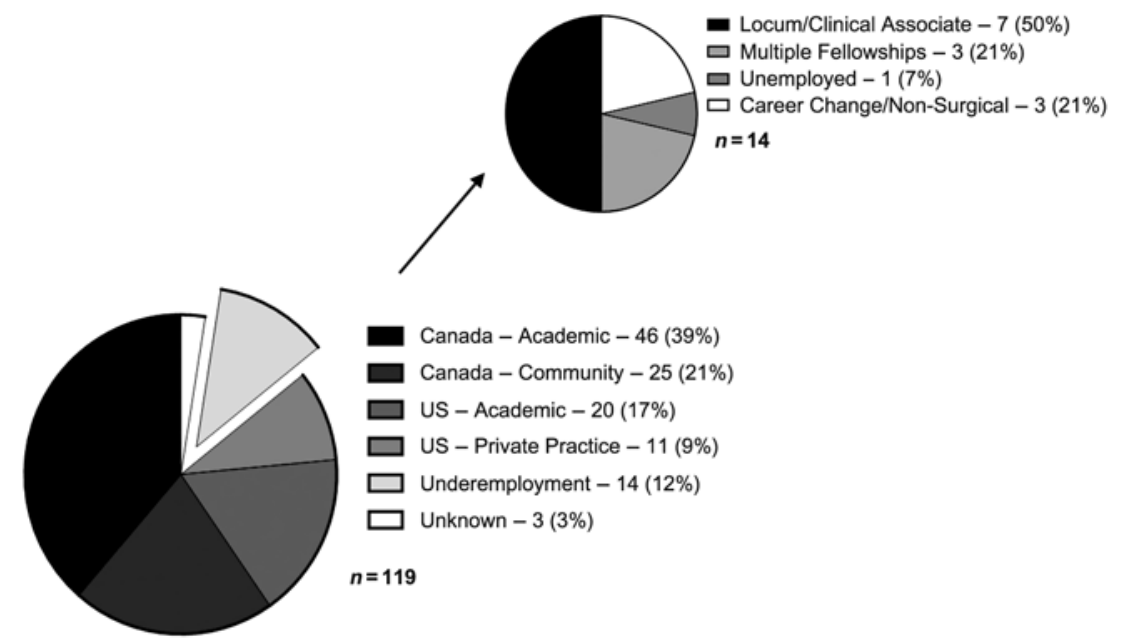

Figure 3: Employment status of neurosurgery trainees $(n=119)$ and sub-classification of trainees who were underemployed $(n=14)$ as of December 2014. The number beside each employment category represents the number of neurosurgery trainees within that category, with $\%$ of total in parentheses.

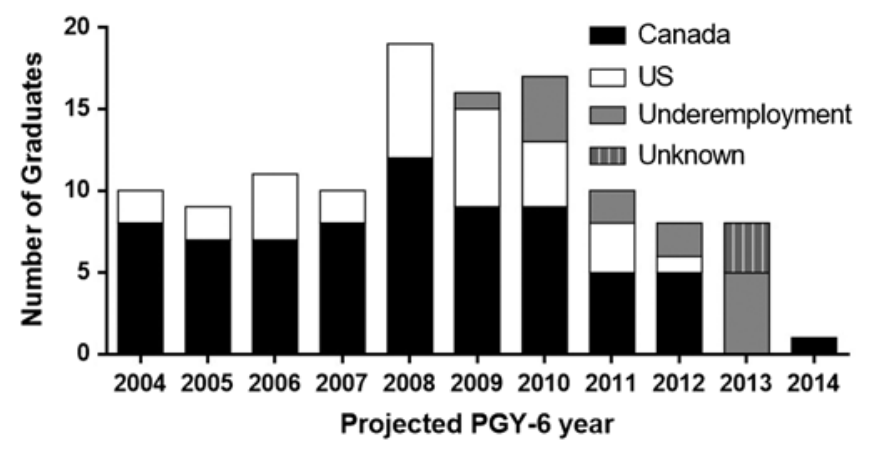

Figure 4: Employment status of neurosurgery trainees based on projected PGY-6 year as of December 2014.

2008 were identified and included in this analysis. These neurosurgery trainees represented all 14 residency training programs across Canada (see Figure 1). There was a 5:1 male:female ratio in neurosurgery trainees $(119(83 \%)$ vs. $24(17 \%))$. Figure 2 shows the number of neurosurgery trainees based on projected PGY-6 year and actual graduating PGY-6 year. The mean delay between projected and actual PGY-6 years was 0.8 years (standard deviation $(\mathrm{SD})=1.4$ years, range $0-8$ years, $n=129$ ).

\section{Employment Outcomes}

Career outcome data as of 2015 were applicable for 119 neurosurgical trainees with an additional 24 trainees still in residency or pursuing their first clinical fellowship. Overall, $60 \%$ of trainees found employment in Canada, while $26 \%$ were employed in the USA (see Figure 3). Also, 56\% of trainees secured academic positions whereas $30 \%$ found employment in community practice or private practice. There was an average of 1.4 years between completion of residency and securing the first permanent employment position, if applicable $(\mathrm{SD}=0.8$ years, range $0-4$ years, $n=102$ ).

At the completion of the study period, underemployment was observed in $12 \%$ of graduates (14/119, see Figure 3). Underemployment at any time within 5 years of residency completion was observed in $20 \%$ of all trainees (24/119), with a mean underemployment duration of 1.8 years $(\mathrm{SD}=1.0$ years, range 0.5-3.5 years, $n=24$ ). Underemployment has affected $18 \%$ $(17 / 95)$ of male trainees and $33 \%(7 / 21)$ of female trainees, 
Table 1: Pursuit of research pre-residency, within residency, or post-residency among neurosurgery trainees

\begin{tabular}{l|c|c|c}
\hline Research degree & $\begin{array}{c}\text { Pre-residency } \\
\text { research }(\boldsymbol{n}=\mathbf{1 4 3})\end{array}$ & $\begin{array}{c}\text { In-folded research } \\
(\boldsymbol{n}=\mathbf{1 4 3})\end{array}$ & $\begin{array}{c}\text { Post-residency } \\
\text { research }(\boldsymbol{n}=\mathbf{1 2 9})\end{array}$ \\
\hline $\mathrm{MSc}$ & $13(9 \%)$ & $20(14 \%)$ & $6(5 \%)$ \\
\hline $\mathrm{PhD}$ & $12(8 \%)$ & $25(18 \%)$ & $2(2 \%)$ \\
\hline Research > 1 year & 0 & $6(4 \%)$ & 0 \\
\hline Any research & $25(18 \%)$ & $51(36 \%)$ & $8(6 \%)$ \\
\hline $\begin{array}{l}\text { No research degree } \\
\text { or research } \\
\leq 1 \text { year }\end{array}$ & $118(83 \%)$ & $92(64 \%)$ & $121(94 \%)$ \\
\hline
\end{tabular}

Table 2: Location of in-folded research institution $(n=51)$

\begin{tabular}{l|c}
\hline Location of In-folded research institution & Number of graduates \\
\hline Canada - same institution & $36(71 \%)$ \\
\hline Canada - different institutions & $3(6 \%)$ \\
\hline USA & $8(16 \%)$ \\
\hline Europe & $1(2 \%)$ \\
\hline Unknown & $3(6 \%)$ \\
\hline
\end{tabular}

Table 3: Employment outcomes stratified by pursuit of research $(n=116)$

\begin{tabular}{c|c|c|c}
\hline & $\begin{array}{c}\text { Full } \\
\text { employment }\end{array}$ & $\begin{array}{c}\text { Academic } \\
\text { appointment }\end{array}$ & Canadian appointment \\
\hline $\begin{array}{c}\text { Pre-residency } \\
\text { research }\end{array}$ & $16 / 21(76 \%)$ & $16 / 21(76 \%)$ & $15 / 21(71 \%)$ \\
\hline $\begin{array}{c}\text { No pre-residency } \\
\text { research }\end{array}$ & $76 / 95(80 \%)$ & $50 / 95(53 \%)$ & $56 / 95(59 \%)$ \\
\hline $\begin{array}{c}\text { Pre-residency } \\
\text { PhD }\end{array}$ & $7 / 10(70 \%)$ & $9 / 10(90 \%)$ & $8 / 10(80 \%)$ \\
\hline $\begin{array}{c}\text { No pre-residency } \\
\text { PhD }\end{array}$ & $85 / 106(80 \%)$ & $57 / 106(54 \%)$ & $63 / 106(59 \%)$ \\
\hline $\begin{array}{l}\text { In-folded } \\
\text { research }\end{array}$ & $33 / 35(94 \%)$ & $30 / 35(86 \%)$ & $18 / 35(51 \%)$ \\
\hline $\begin{array}{c}\text { No In-folded } \\
\text { research }\end{array}$ & $59 / 81(73 \%)$ & $36 / 81(44 \%)$ & $53 / 81(65 \%)$ \\
\hline \begin{tabular}{l} 
In-folded PhD \\
\hline $\begin{array}{l}\text { No In-folded } \\
\text { PhD }\end{array}$
\end{tabular} & $15 / 15(100 \%)$ & $13 / 15(87 \%)$ & $6 / 15(40 \%)$ \\
\hline
\end{tabular}

although these rates were not significantly different $(p=0.138)$. Current employment status based on projected PGY-6 year is seen graphically in Figure 4. When categorizing trainees based on residency location (western provinces, Ontario, Québec, and Maritimes), there were no significant differences in overall underemployment rates.

\section{Pursuit of Research}

Overall, 55\% (79/143) have obtained a post-graduate degree ( $\mathrm{MSc}$ or $\mathrm{PhD}$ ) or pursued an extended research period of more
Table 4: Fellowship status and location

\begin{tabular}{l|c}
\hline Fellowship location & Number of graduates $(\boldsymbol{n}=\mathbf{1 2 9})$ \\
\hline No fellowship & $8(6 \%)$ \\
\hline Canada & $42(33 \%)$ \\
\hline USA & $62(48 \%)$ \\
\hline Other & $3(2 \%)$ \\
\hline Unknown & $14(11 \%)$ \\
\hline
\end{tabular}

than 1 year either prior, during, or after neurosurgery residency training (see Table 1). A majority $(71 \%)$ of trainees pursuing in-folded research did so at their home institution (see Table 2). The proportion of trainees who pursued in-folded research was not significantly different based on projected PGY-6 year between 2009 and 2014 inclusive compared with PGY-6 year between 2004 and 2008 inclusive (35\% vs. 37\%, $p=0.861$ ). Also, pursuit of in-folded research was not significantly different between male and female trainees (37\% vs. $29 \%, p=0.641$ ).

Neurosurgery trainees who pursued in-folded research were more likely to obtain full employment without any prior underemployment compared with those who did not pursue in-folded research (94\% vs. $73 \%, p=0.011$, see Table 3). However, having any pre-residency research degree was not specifically associated with full employment after residency completion $(p=0.767)$. Also, having any research training, whether pre-residency, within residency, or post-residency, did not significantly affect the rate of full employment compared with trainees without research training ( $82 \%$ vs. $75 \%, p=0.479$ ).

Pursuing in-folded research was significantly associated with obtaining a permanent academic position, compared with trainees without in-folded research $(86 \%$ vs. $44 \%, p<0.001)$. There was a trend toward obtaining a permanent academic position among neurosurgery trainees with pre-residency research degrees $(p=0.055)$. Having a $\mathrm{PhD}$ degree specifically, whether obtained in pre-residency or within residency, was associated with securing a permanent academic position $(p=0.042$ and $p=0.013$, respectively).

Obtaining a pre-residency research degree or pursuing in-folded research was not associated with securing employment in Canada. This result remains consistent when looking specifically at preresidency $\mathrm{PhD}$ degrees. However, there was a trend toward US employment after obtaining an in-folded $\mathrm{PhD}$ degree $(p=0.09)$.

In-folded research pursuit based on trainees' projected PGY-6 year can be seen graphically in Figure 5 .

\section{Fellowship Training}

At least 83\% (107/129) of neurosurgery trainees went on to fellowship training after residency completion (see Table 4). Excluding those with unknown fellowship status, the proportion of trainees with fellowship experience increases to $93 \%$ (107/115). Complex spine fellowship was the most commonly pursued subspecialty (see Figure 6). Trainees who had fellowship training in both endovascular neurosurgery and open vascular/ skull base were classified under the "endovascular" category. The proportion of trainees with subsequent fellowship training after residency completion was not significantly different for those 


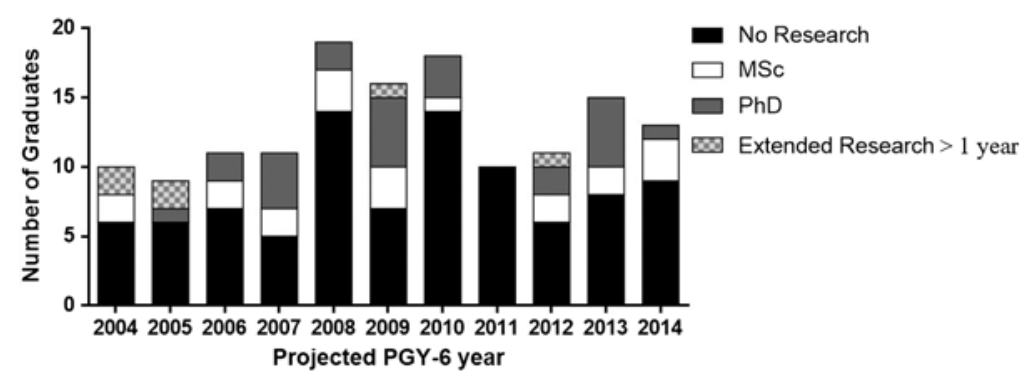

Figure 5: Pursuit of in-folded research based on projected PGY-6 year.

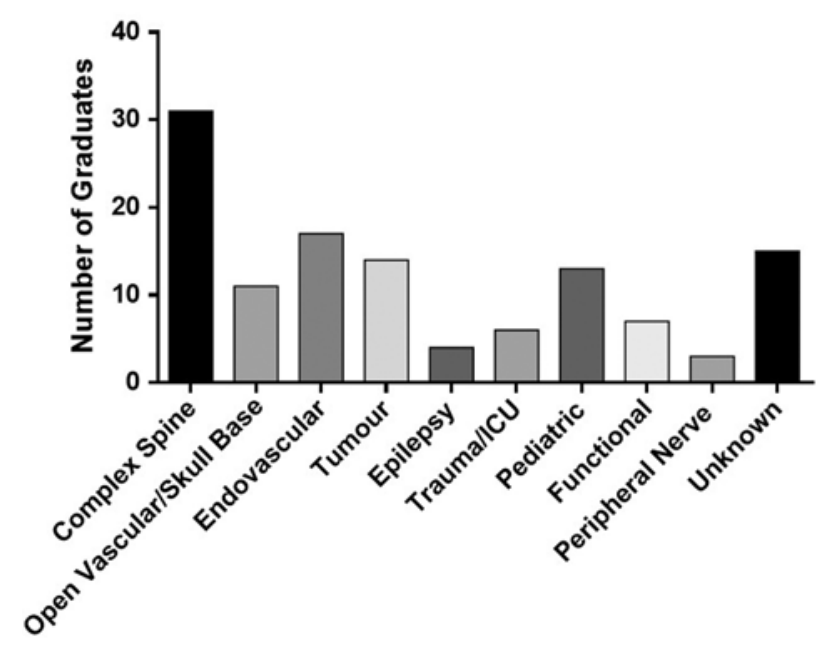

Figure 6: First clinical fellowship subspecialty selection.

whose projected PGY-6 year was between 2009 and 2014 inclusive compared with those whose PGY-6 year was between 2004 and 2008 inclusive $(91 \%$ vs. 96\%, $p=0.464$, excludes those with unknown fellowship status). Also, among trainees with known fellowship status, there was no significant difference among males and females regarding pursuit of fellowship training ( $92 \%$ vs. $100 \%, p=0.354)$.

There was no significant association between pursuit of fellowship and obtaining full employment without any prior underemployment ( $p=1.000$, see Table 5). Specifically going to the USA for fellowship was not associated with obtaining full employment $(p=0.233$, see Table 5$)$. Specific subspecialty choice was also not associated with full employment (data not shown).

Fellowship training was significantly associated with securing a permanent academic position ( $p<0.001$, see Table 5). However, this significant association was lost if looking specifically at fellowship training in the USA $(p=0.112)$. Among the subspecialties, trainees who pursued a complex spine fellowship were less likely to obtain a permanent academic position compared to other fellowship subspecialties (44\% vs. $71 \%, p=0.019)$.

Fellowship training (vs. no fellowship training) was not associated with securing employment in Canada (see Table 5). However, there was a trend toward significance between pursuing a fellowship in the USA and obtaining permanent employment outside of Canada ( $p=0.069)$. Specific subspecialty choice was not associated with employment in Canada (data not shown).

Fellowship pursuit based on trainees' projected PGY-6 year can be seen graphically in Figure 7.

\section{Discussion}

This study is the first to provide data regarding underemployment among Canadian neurosurgery trainees. We identified a $12 \%$ underemployment rate among neurosurgery trainees during the 11-year period of this study, with $20 \%$ of trainees being underemployed at some point within 5 years of completion of residency.

The RCPSC employment survey involving newly certified specialists and subspecialists from 2011 to 2012 revealed that $38 \%(8 / 21)$ of newly certified neurosurgeons had not secured employment at the time of the exit survey. ${ }^{3}$ This result should be interpreted with caution given that most neurosurgery trainees would be pursuing their first clinical fellowship at the time of the survey and only 44\% (22/50) of all neurosurgery trainees in 2011 and 2012 responded to the survey, which includes both CMGs and foreign medical graduates (FMGs). ${ }^{3}$ Lastly, in that survey, employment was defined to include full-time positions as well as locums and part-time positions. ${ }^{3}$

Even though Canadian neurosurgery trainees are not board eligible or board certified, some are securing employment in the USA ( $26 \%$ in our study). However, Canadian-trained neurosurgeons must obtain work visas sponsored by an employer in order to work in the USA. ${ }^{10}$ Notwithstanding various negotiations and discussions, there has been no movement to accredit Canadian neurosurgery training and subsequent changes to training requirements in both countries may serve to perpetuate this.

In a response to the initial changes in ABNS board eligibility, Dr. Bryce Weir stated in 2011 that, "no effective action was taken" regarding the overproduction of Canadian-trained neurosurgeons. ${ }^{11}$ In the last several years, the four neurosurgery training programs in Quebec have estimated their future provincial need for neurosurgeons and have adjusted the number of neurosurgery residency positions accordingly. For example, in the Canadian Resident Matching Service (CaRMS) 2015 match process, only two of the four Quebec neurosurgery residency programs had CMG CaRMS positions, with plans to alternate which programs would receive residents moving forward. ${ }^{12}$ In 2017, only one of the four Quebec neurosurgery residency programs had a CMG CaRMS position. ${ }^{12}$ Dr. J. Max Findlay has advocated limiting neurosurgery training spots across the country. ${ }^{5}$ A coordinated response may be needed to reduce neurosurgery residency positions, of which there were 19 CaRMS CMG positions in the 2018 match. ${ }^{12}$ The subsequent need for service coverage in the face of proposed limitations in neurosurgery trainee positions may lead to increased hiring of physician assistants and/or nurse practitioners. The number of residency positions is determined independently within provincial jurisdictions and no current national governing 
Table 5: Employment outcomes stratified by fellowship training

\begin{tabular}{l|c|c|c}
\hline & $\begin{array}{c}\text { Full } \\
\text { employment }\end{array}$ & $\begin{array}{c}\text { Academic } \\
\text { appointment }\end{array}$ & Canadian appointment \\
\hline Fellowship & $73 / 94(78 \%)$ & $59 / 94(63 \%)$ & $53 / 94(56 \%)$ \\
\hline No fellowship & $6 / 8(75 \%)$ & $0 / 8(0 \%)$ & $6 / 8(75 \%)$ \\
\hline US fellowship & $47 / 57(83 \%)$ & $37 / 57(56 \%)$ & $28 / 57(49 \%)$ \\
\hline $\begin{array}{c}\text { Canada or other } \\
\text { fellowship }\end{array}$ & $32 / 45(71 \%)$ & $22 / 45(49 \%)$ & $31 / 45(69 \%)$ \\
\hline
\end{tabular}

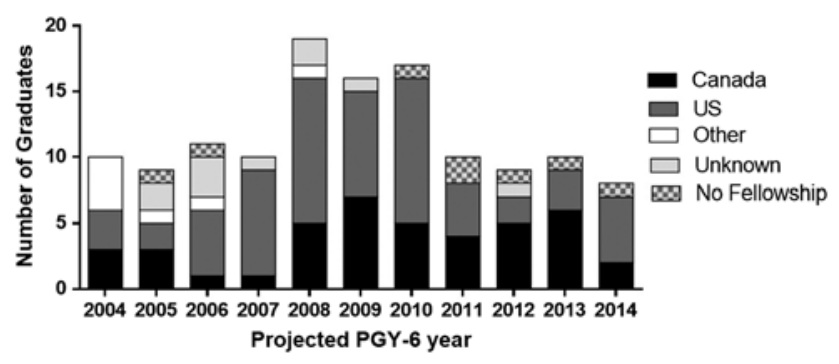

Figure 7: Pursuit of fellowship based on projected PGY-6 year.

body exists that can unilaterally limit residency positions in one province vs. another. Portability of RCPSC certification throughout Canada without a national body overseeing national healthcare requirements may prove detrimental in the future.

It is extremely challenging to forecast healthcare needs. Within the last 20 years, there was prediction of a looming neurosurgeon shortage which has shifted to a surplus of neurosurgeons in a relatively short time period. ${ }^{4,13}$ This difficulty in forecasting is not unique to Canada, as the USA also had fluctuations in the forecasting of future neurosurgery needs. ${ }^{14}$ Also, despite a neurosurgeon to population ratio of 1:65,580, there is apparently still a relative shortage of neurosurgeons in the USA given the relative abundance of job advertisements $(>300) .{ }^{14}$ It should be noted that a surplus of trained Canadian neurosurgeons can still lead to a relative shortage of neurosurgeons working within the infrastructure of the Canadian health care system. In fact, the longest wait times to see a specialist were for neurosurgery. ${ }^{15}$

Given the aging population and current wait times to see neurosurgeons, especially for patients with degenerative spine conditions, another strategy would be to hire more neurosurgeons to accommodate the surplus of neurosurgery trainees. The neurosurgical community needs to continue to advocate for increased healthcare resources devoted to neurosurgery. However, even then, an increase in neurosurgery positions would not be a longterm solution if there continues to be an imbalance in the training and retirement of neurosurgeons. Neurosurgeon to population ratio has already increased steadily in Canada from $0.7 / 100,000$ in 1995 to $0.9 / 100,000$ in $2013 .{ }^{16}$

In our study, trainees who pursued in-folded research were more likely to secure full employment and obtain an academic appointment. Similarly in the USA, neurosurgeons having both $\mathrm{MD}$ and $\mathrm{PhD}$ degrees were associated with having academic appointments and were more likely to obtain National Institute of Health (NIH) funding. ${ }^{17}$ In our study, trainees who pursued fellowships were more likely to obtain an academic appointment, but not more likely to obtain full employment. Based on data from one US residency program, pursuit of subspecialty fellowship was predictive for future academic appointment with other predictive factors being favorable evaluations during junior and chief residency. ${ }^{18}$ However, publications, presentations, and awards received during residency were not predictive. ${ }^{17}$

This study has some important limitations. First, neurosurgical employment is somewhat fluid and the data presented here reflect a survey at a single point in time, rather than an analysis of a continuum. Full-time employment in neurosurgery may not be the goal for every trainee, given some who may wish to have a more desirable work-life balance. Although virtually all current CMG neurosurgeons working in Canada have been identified, this study may have missed some Canadian trainees working in the USA or abroad who completed their residency in the early portion of the study period. Reliance on information from the public domain may also be a limitation, although we endeavored to ensure all information was current and accurate at the time of the survey. Data regarding whether trainees had successfully passed the Royal College examination were not available. Because this study involved extensive exploratory analysis of the data, multiple statistical tests were performed leading to an issue regarding multiple comparisons and Type I errors.

Future studies can involve interviewing current underemployed trainees and current chairs of Canadian neurosurgery programs, to obtain a more in-depth understanding of the current employment dynamics in Canada. Creation of a centralized prospective registry for issues surrounding neurosurgeon human resources would also be beneficial for planning health care resource allocation. Also, future studies can investigate the reasons trainees pursued employment outside of Canada. Finally, further insight can be found by surveying trainees regarding their overall job satisfaction 5 and 10 years after residency completion.

\section{Conclusion}

Underemployment in neurosurgery is a significant concern in Canada, with one in five trainees affected. Pursuit of research within residency was associated with academic appointment and full employment status. Pursuit of fellowship training after residency was associated with academic appointment, but not with full employment status. With the scope of the underemployment issue now defined, a national coordinated effort will be needed to address what will potentially continue to be an ongoing issue.

\section{ACKNOWLEDGements}

We would like to acknowledge the assistance of CNSS active and junior members for gathering data for this study.

\section{Disclosures}

The authors have no relevant disclosures.

\section{Statement of Authorship}

MKT and IGF conceived the idea and drafted the manuscript. All authors (MKT, IGF, JMF, SPL, MCW, and BDT) critically reviewed and edited the manuscript, and approved the final version. 


\section{REFERENCES}

1. Wilson MP, Pugh JA. Increasing the appeal of neurosurgery to qualified medical students in Canada. Can J Neurol Sci. 2012;39:667-9.

2. The American Board of Neurological Surgery. Available at: http://www.abns.org/content/primary_certification_process.asp; accessed January 17, 2015.

3. Royal College of Physicians and Surgeons. Available at: http:// www.royalcollege.ca/portal/page/portal/rc/advocacy/policy/hrh/ examining_specialist_physician_employment; accessed January $17,2015$.

4. Desbiens R, Elleker MG, Goldsand G, et al. Current educational issues in the clinical neurosciences. Can J Neurol Sci. 2001; 28:283-92.

5. Findlay JM. Manpower in the Canadian neurosurgical workforce: is a crisis looming? Can J Neurol Sci. 2004;31:138.

6. Kondro W. New neurosurgeons left jobless: where's the plan? CMAJ. 2004;170(9):1377-8.

7. Toyota BD. Canadian neurosurgical manpower: need for selfdetermination. Can J Neurol Sci. 2006;33:123-4.

8. Woodrow SI, O'Kelly C, Hamstra SJ, Wallace MC. Unemployment in an underserviced specialty?: the need for co-ordinated workforce planning in Canadian neurosurgery. Can J Neurol Sci. 2006:33:170-4.

9. TCPS2 - Tri-council policy statement: Ethical conduct for research involving humans. 2014; Available at: http://www.pre.ethics.gc.
ca/eng/policy-politique/initiatives/tcps2-eptc2/Default/; accessed January 17, 2015.

10. How to work as a physician in the US if you are a foreign medical graduate. Available at: http://www.rosmansearch.com/ files/howto.pdf; accessed January 17, 2015.

11. Weir B. A history of neurosurgery in Canada. Can J Neurol Sci. 2011;38:203-19.

12. Canadian resident matching service. Available at: http:// www.carms.ca/; accessed January 17, 2019.

13. Hugenholtz H. Neurosurgery workforce in Canada, 1996 to 2011. Can Med Assoc J. 1996;155(1):39-48.

14. Rosman J, Slane S, Dery B, Vogelbaum MA, Cohen-Gadol AA, Couldwell WT. Is there a shortage of neurosurgeons in the United Stated? Neurosurgery. 2013;73:354-66.

15. Thind A, Stewart M, Manuel D, et al. What are the wait times to see a specialist? An analysis of 26,942 referrals in southwestern Ontario. Healthc Policy. 2012;8(1):80-91.

16. Canadian Medical Association (CMA) Neurosurgery Profile. Available at: https://www.cma.ca/Assets/assets-library/document/en/ advocacy/Neurosurgery-e.pdf; accessed January 17, 2015.

17. Choi BD, DeLong MR, DeLong DM, Friedman AH, Sampson JH. Impact of $\mathrm{PhD}$ training on scholarship in a neurosurgical career. J Neurosurg. 2014;120:730-5.

18. Lawton MT, Narvid J, Quinones-Hinojosa A. Predictors of neurosurgical career choice among residents and residency applicants. Neurosurgery. 2007;60:934-9. 